\title{
Two Pituitary Neuroendocrine Tumors (PitNETs) with Very High Proliferation and TP53 Mutation - High-Grade PitNET or PitNEC?
}

\author{
Wolfgang Saeger ${ }^{1}\left[\right.$ Christian Mawrin ${ }^{2} \cdot$ Matthias Meinhardt $^{3} \cdot$ Annika K. Wefers $^{4} \cdot$ Frank Jacobsen $^{5}$
}

Accepted: 5 October 2021 / Published online: 20 October 2021

(c) The Author(s) 2021, corrected publication 2021

\begin{abstract}
We report two pituitary neuroendocrine tumors (PitNETs) with very high Ki67 labeling indices, many mitoses and TP53 mutation (nearly all tumor cell nuclei were positive for p53). One of the tumors had bone and liver metastases. One was a corticotroph cell tumor; the other was a lactotroph tumor. The classification of these tumors is the subject of this discussion. Traditionally, pituitary carcinomas are only diagnosed by demonstration of metastases according to the 2017 WHO classification. In contrast, neuroendocrine neoplasms of the gastrointestinal tract and pancreas are classified as either well differentiated NETs that are graded as G1, G2, and G3 based on proliferation as determined by Ki67 indices of $\leq 3,3-20$ and $>20 \%$, and/or $<2,2-20$, and $>20$ mitoses per 10 high-power field respectively, or as neuroendocrine carcinomas (NECs) that are poorly differentiated neoplasms with mitoses $>20 / \mathrm{HPF}$ and/or a Ki67 index $>20 \%$. With the reclassificiation of PitNETs, in our opinion, the adequate term for the well-differentiated corticotroph tumor that we report is a PitNET G3, whereas the undifferentiated prolactin tumor should be classified as PitNEC. This report expands the spectrum of pituitary neuroendocrine neoplasms.
\end{abstract}

Keywords Pituitary $\cdot$ Neuroendocrine carcinoma $\cdot$ PitNEC $\cdot$ PitNET

Wolfgang Saeger

w.saeger@uke.de

Christian Mawrin

christian.mawrin@med.ovgu.de

Matthias Meinhardt

Matthias.Meinhardt@uniklinikum-dresden.de

Annika K. Wefers

a.wefers@uke.de

Frank Jacobsen

f.jacobsen@uke.de

1 Institute of Neuropathology, University of Hamburg, UKE, 20246 Hamburg, Germany

2 Institute of Neuropathology, Otto-Von-Guericke University, 39120 Magdeburg, Germany

3 Institute of Neuropathology, University Clinic Carl Gustav Carus, 01307 Dresden, Germany

4 Institute of Neuropathology, University of Hamburg and Mildred Scheel Cancer Career Center HaTriCS4, UKE, 20246 Hamburg, Germany

5 Institute of Pathology, University of Hamburg, UKE, 20246 Hamburg, Germany

\section{Introduction}

The 2017 Consensus Conference of the International Agency for Research on Cancer developed the classification of neuroendocrine neoplasms (NENs) and distinguished well-differentiated neuroendocrine tumors (NETs) from poorly differentiated neuroendocrine carcinomas (NECs) [14]. This was based on the criteria used for the digestive system, which are now widely accepted (WHO classification 2019) [7]. The definitions are shown in Table 1. Whereas in NET G1 metastases are very rare [20], metastases from NET G2 are not extremely rare and metastases from NEC are frequent [5].

The International Pituitary Pathology Club (IPPC) proposed the term "pituitary neuroendocrine tumors" (PitNET) [1-3] instead of pituitary adenoma. However, pituitary carcinomas remained as defined in the 2017 WHO classification by the development of metastases [12].

In our material, tumors previously classified as "pituitary adenoma" grow invasively in 49\% [16] and metastasize in $0.06-0.1 \%$ of surgical specimens [15]. These properties are in contrast to the term "adenoma," which, according to the principles of general tumor pathology, denotes a 
Table 1 Grading in the classification of neuroendocrine tumors (NET) and neuroendocrine carcinomas (NEC) of the digestive system [7]

\begin{tabular}{llll}
\hline Term & Differentiation & Mitoses & Ki-67 index \\
\hline NET G1 & Well-differentiated & $<2 / 10 \mathrm{HPF}$ & $<3 \%$ \\
NET G2 & Well-differentiated & $2-20 / 10 \mathrm{HPF}$ & $3-20 \%$ \\
NET G3 & Well-differentiated & $>20 / 10 \mathrm{HPF}$ & $>20 \%$ \\
$\begin{array}{c}\text { NEC, small cell } \\
\text { type }\end{array}$ & $\begin{array}{c}\text { Poorly differenti- } \\
\text { ated }\end{array}$ & $>20 / 10 \mathrm{HPF}$ & $>20 \%$ \\
$\begin{array}{c}\text { NEC, large cell } \\
\text { type }\end{array}$ & $\begin{array}{c}\text { Poorly differenti- } \\
\text { ated }\end{array}$ & $>20 / 10 \mathrm{HPF}$ & $>20 \%$ \\
\hline
\end{tabular}

non-invasive tumor that does not metastasize. Therefore, in comparison to the gastrointestinal NET G1 and G2, PitNET is an adequate term for pituitary neuroendocrine tumors instead of adenomas [1,2]. PitNET G1 may be used for non-invasive and non-aggressive tumors, and PitNET G2 may be used for aggressive tumors. Ki67 indices of more than $20 \%$ are very rare, and some metastasizing pituitary carcinomas show Ki67 indices of $0-16 \%$ [19] or 0 to $22 \%$ [18]; PitNET G3 as defined by a Ki-67 index of more than $20 \%$ should be very rare.

The term neuroendocrine carcinoma of the pituitary (PitNEC) is not established in pituitary pathology as poorly differentiated NECs of the pituitary (PitNECs) seem not to exist [14]. Therefore, we would like to turn your attention to two pituitary tumors with an extremely high Ki67 index and evidence of TP53 mutation and discuss the problem of identifying PitNEC,

\section{Methods}

Tumors were fixed in $10 \%$ buffered formalin, embedded in paraffin, and stained with hematoxylin-eosin and PAS. Immunostaining was performed with primary antibodies against GH, Prolactin, ACTH, TSH, FSH, LH, alphasubunit, PIT1, TPIT, SF1, synaptophysin, chromogranin, S100 protein, Keratins (AE1/AE3, Cam5.2), p53, and Ki67 (MiB1).

DNA panel sequencing was performed using a selfcustomized targeted panel manufactured by Qiagen (CDHS-21330Z-424). This panel targets the complete coding regions and splice-sites of six genes (ATRX, EGFR, $N F 1, N F 2$, PTEN, TP53), as well as mutation hotspots of 14 further genes (AKT, BRAF, CTNNB1, FGFR1, FGFR2, H3F3A, HIST1H3B, HIST1H3C, IDH1, IDH2, KRAS, PI3CA, PIK3R1, TERT-promoter). The library was constructed according the manufacturer's instructions. Sequencing was performed on an Illumina MiniSeq sequencing system (paired-end, $2 \times 151 \mathrm{bp}$, average coverage $500 \times$ ). Data was analyzed with the Qiagen CLC

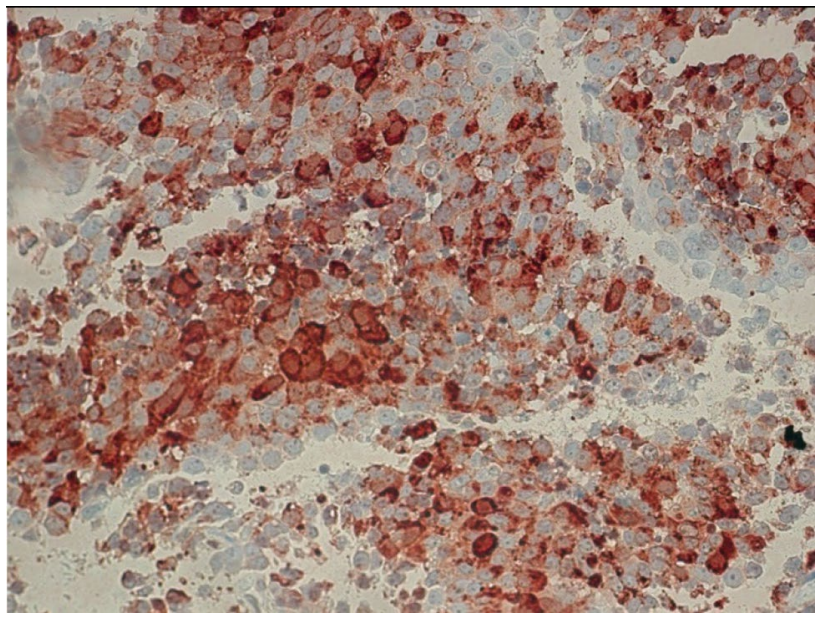

Fig. 1 Case 1: ACTH-PitNET G3. Anti-ACTH-hematoxylin, magnification $440 \times$

Genomics workbench, using a self-customized workflow. Variants were annotated with information from the 1000 genome project, dbSNP, ClinVar, and COSMIC. Only variants with an allele frequency $\geq 5 \%$ and a total target coverage of $\geq 40 \times$ were analyzed further. Variants not annotated by ClinVar were additionally analyzed with VarSome (www.varsome.com).

\section{Results}

\section{Case 1}

A 53-year-old male suffered from Cushing's disease with elevated cortisol and ACTH levels as well as arterial hypertension and diabetes mellitus. The pituitary macrotumor was resected transsphenoidally in an external hospital but relapsed and the patient had to undergo reoperation.

The surgical specimens showed a tumor with densely arranged medium-sized cells harboring chromatin-rich nuclei and basophilic, but PAS-negative cytoplasm (Fig. 1). Features of dedifferentiation were not evident. Mitoses were very frequent. Immunostaining for ACTH was moderately positive (Fig. 2), and the transcription factor for pituitary corticotrophs (TPIT) was expressed. The Ki67 index was very high $(60-70 \%)$. P53 was localized in nearly all tumor cell nuclei (Fig. 2).

After surgery, the patient received adjuvant radiation therapy (54 Gy) and systemic therapy with metyrapone ( $3 \mathrm{~g}$ ) and ketoconazole (400 mg). Due to persistently increased ACTH levels, the patient was referred for a third pituitary surgery but MRI of the sellar region did not demonstrate tumor regrowth. Clinical examinations were performed to search for an ectopic source of ACTH. Thoracic and 


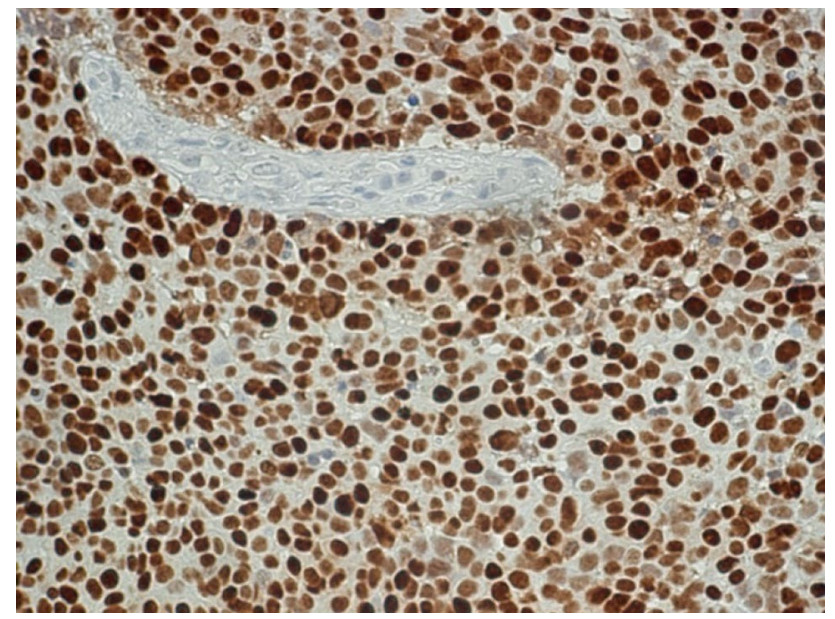

Fig. 2 Case 1: ACTH-PitNET G3. P53-hematoxylin, magnification 440×

abdominal CT revealed multiple metastatic lesions in the liver and in the vertebrae. The adrenal glands were greatly enlarged. A CT-guided biopsy of the liver showed tumor tissue within and outside of the sinusoidal network as multiple, variably large foci. The histology was very similar to that of the pituitary tumor (Fig. 3). Mitoses were very frequent. The Ki67 index was just as high as in the pituitary tumor (60-70\%) (Fig. 4). Immunostaining for ACTH was positive; however, in contrast to the pituitary tumor, the transcription factor TPIT was not expressed in two separate examinations. All other immunostaining was identical to the pituitary tumor (Table 2).

Therefore, we can clearly state that either the tumor in the pituitary and in the liver are metastases of a tumor originating elsewhere, or the pituitary tumor is the primary tumor. This question can be answered by the expression of TPIT in the

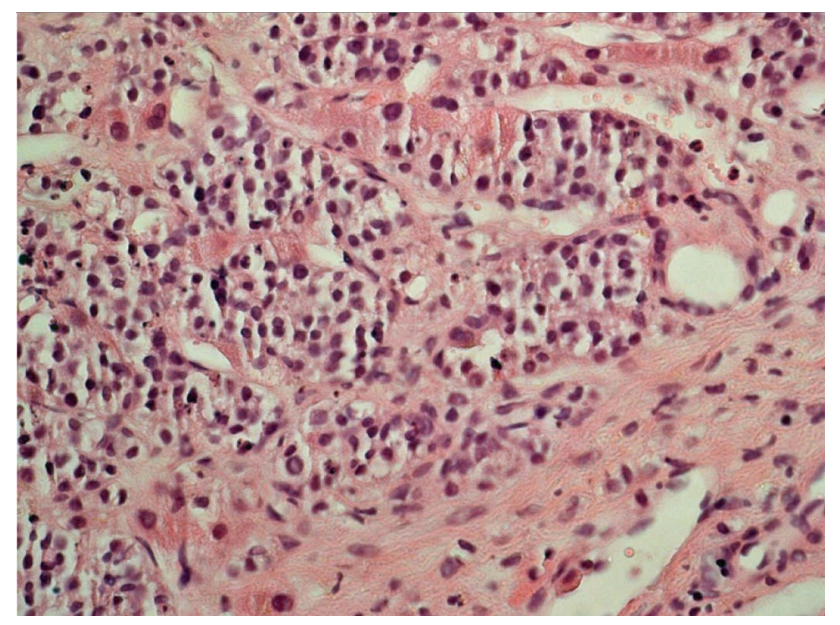

Fig. 3 Case 1: Liver metastasis of ACTH-PitNET G3. Hematoxylineosin stain, magnification $250 \times$

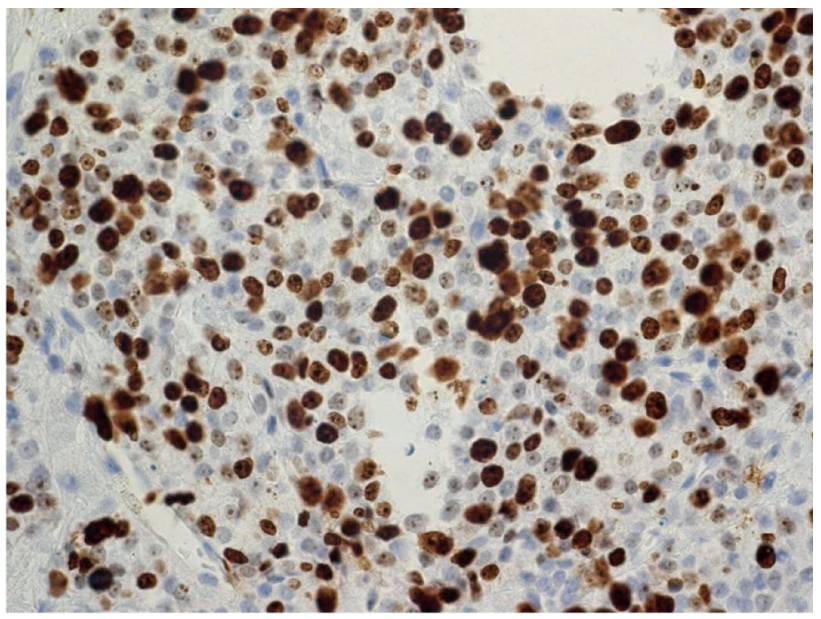

Fig. 4 Case 1: Liver metastasis of ACTH-PitNET G3. Ki-67 (MiB1)-hematoxylin, magnification $440 \times$

pituitary tumor, since this transcription factor is the lineage marker for pituitary corticotrophs. Moreover, we detected the same mutations of TP53 (NM_0005465:c.743G > A) and NF1 (NM_001042492.2:c.1318C > T) in both tumors by DNA panel sequencing. Additionally, we found two PTEN mutations (NM_000314.6:c.388C > T and c.210-1G > A) in the liver tumor only, as well as an ATRX variant of uncertain relevance (NM_000489.4:c.2044A > G).

Due to the metastases, the pituitary tumor would fulfill the 2017 WHO classification criteria for carcinoma; however, without known metastasis, this tumor would have been diagnosed as an adenoma with increased proliferation.

Table 2 Immunostaining of the two pituitary carcinomas

\begin{tabular}{llll}
\hline Antibody & $\begin{array}{l}\text { Case 1 } \\
\text { Pituitary }\end{array}$ & Case 1 Liver & Case 2 Pituitary \\
\hline ACTH & +++ & +++ & 0 \\
T-Pit & +++ & 0 & 0 \\
Prolactin & 0 & 0 & ++ \\
Pit-1 & 0 & 0 & +++ \\
SF-1 & 0 & 0 & 0 \\
GH & 0 & 0 & 0 \\
TSH & 0 & 0 & 0 \\
FSH & 0 & 0 & 0 \\
LH & 0 & 0 & 0 \\
Estrogen recep- & & & +++ \\
$\quad$ tor & & $60 \%$ & $80 \%$ \\
Ki-67 & $60 \%$ & $>95 \%$ & $>80 \%$ \\
P53 & $100 \%$ & +++ & +++ \\
Synaptophysin & +++ & - & $(+)$ \\
Chromogranin & - & +++ & - \\
Keratin AE1/ & +++ & & \\
$\quad$ AE3 & & &
\end{tabular}




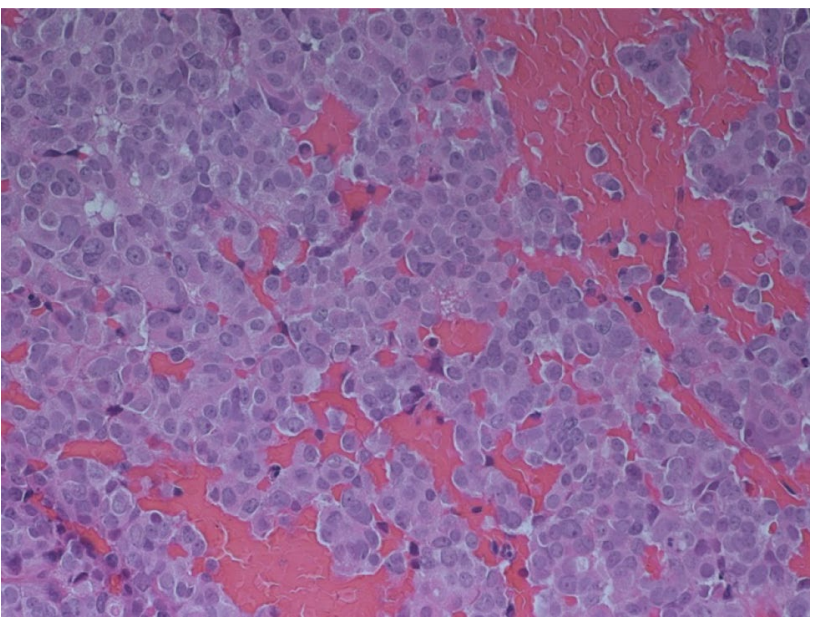

Fig. 5 Case 2: Prolactin-PitNEC. Hematoxylin-eosin stain: magnification $440 \times$

Following the principles of NET, this relatively welldifferentiated tumor should be designated as NET G3 (high grade NET).

\section{Case 2}

A young woman aged 17 had suffered from an embryonal rhabdomyosarcoma of the orbit at the age of 3 years as well as an atypical plexus papilloma (WHO grade II) of the lateral ventricle at the age of 6 years. The rhabdomyosarcoma was treated with vincristine, actinomycin, and ifosfamide. The plexus papilloma was treated by gross total resection.

Eleven years later, a tumor in the sellar region was diagnosed and transsphenoidally resected with a presumptive diagnosis of recurrent rhabdomyosarcoma. Preoperative prolactin levels were moderately increased $(762 \mathrm{mU} / \mathrm{L}$, reference range:

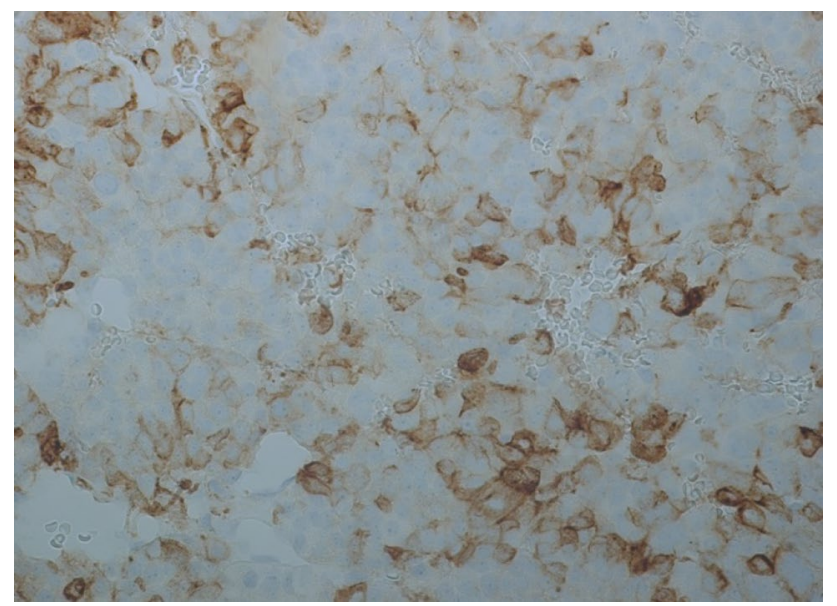

Fig. 6 Case 2: Prolactin-PitNEC. Anti-Prolactin-hematoxylin, magnification $440 \times$

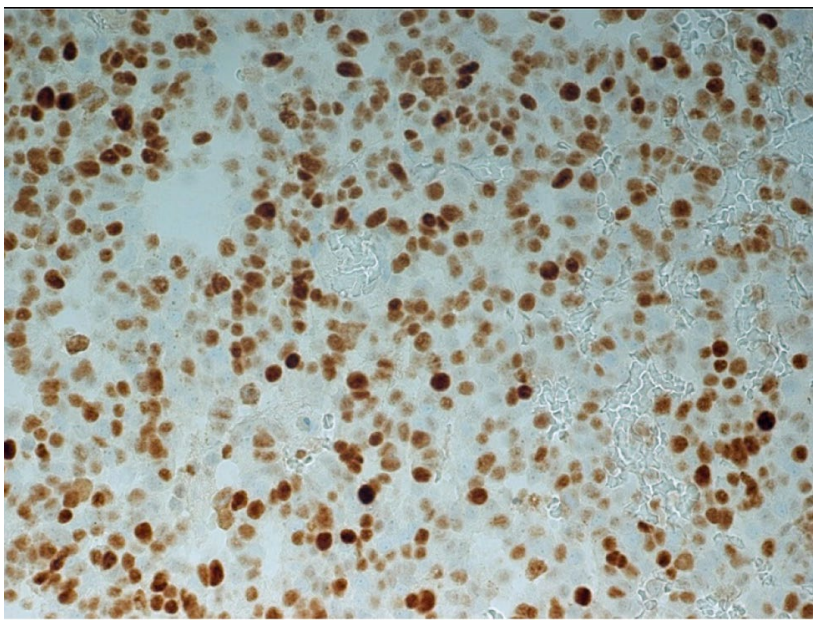

Fig. 7 Case 2: Prolactin-PitNEC. P53-hematoxylin: magnification 440×

102-496). One week after surgery, the prolactin level was $653 \mathrm{mU} / \mathrm{L}$, and 6 weeks after surgery, it remained at $653 \mathrm{mU} / \mathrm{L}$.

The sellar lesion was a pituitary neuroendocrine tumor with diffuse arrangement of small to medium-sized cells and many mitoses (Fig. 5). Immunostaining (Table 2) revealed strong expression of PIT1, moderate expression of prolactin (Fig. 6), and strong nuclear expression of estrogen receptor. Nuclear staining for p53 was intense (Fig. 7), and the Ki67 index exceeded 50\% (Fig. 8). DNA panel sequencing revealed a TP53 mutation (NM_000546.5:c.731G > A).

Following the principles of NET, in contrast to a highly differentiated sparsely or densely granulated lactotroph tumor, this neoplasm was composed of smaller cells without the typical immunostaining pattern for prolactin (Golgi pattern in the sparsely granulated type or strong diffuse staining in the densely granulated type). Due to the lack of these

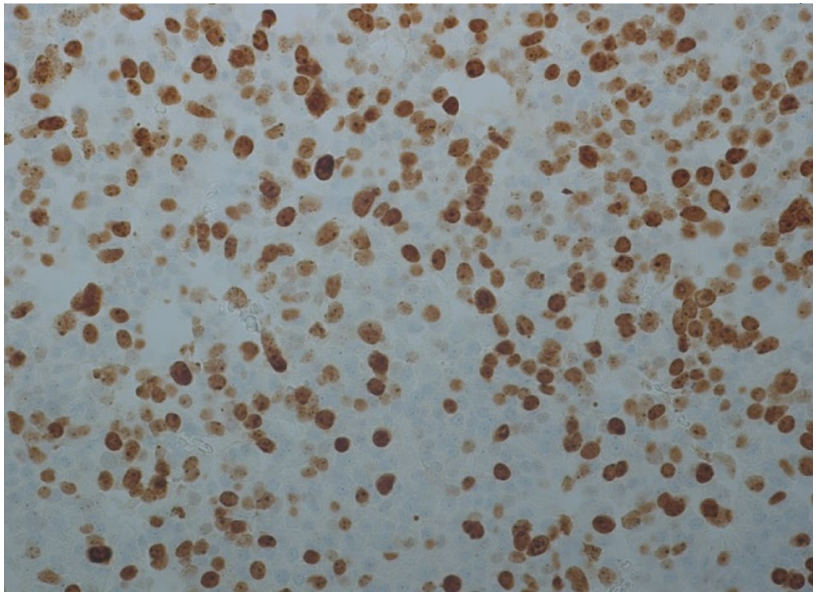

Fig. 8 Case 2: Prolactin-PitNEC. Ki-67 (MiB-1)-hematoxylin: magnification $440 \times$ 
hallmarks, this tumor should be designated as PitNEC or at least as a questionable PitNEC.

\section{Discussion}

One problem regarding the histopathology of case 1 was the negative staining for TPIT in the liver metastasis, whereas ACTH was positive. In the pituitary primary tumor, TPIT and ACTH were strongly expressed. We have no explanation for this fact, since an ACTH-expressing pituitary tumor must express TPIT [17]. It may be that the harboring tissue (liver) plays a role.

Two cases published in the literature can be compared with our tumors: (1) The case report of Pasquel et al. (2013) [13] described a nonfunctioning PitNET with a Ki67 index of 30 to $80 \%$. Due to the lack of metastases, the authors proposed the term "carcinoma in situ" for this tumor. (2) Guo et al. [6] found an ACTH-expressing metastatic pituitary neoplasm with TP53 mutation and novel gene mutations in ATRX and PTEN genes. The tumor showed high pleomorphism, numerous mitoses, very strong nuclear expression of p53, and a Ki67 index of up to $80 \%$. This tumor appears very similar to our case 1 .

Due to the high Ki67 index, the high number of mitoses, and the extremely strong expression of p53 in the nuclei, both tumors in this study differ from pituitary carcinomas described in the literature and in the 2017 WHO classification [12]. According to the gastrointestinal NETs, both tumors can be named PitNET G3 if they are well differentiated, or PitNEC when they are poorly differentiated. The ACTH-producing neoplasm (case 1) appeared to be well differentiated due to the relatively large cytoplasm, but the prolactin-producing neoplasm (case 2) had scanter cytoplasm and lacked other signs of lactotroph differentiation; therefore, it appeared to be a poorly differentiated neoplasm. These facts show that both NET types - the PitNET G3 and the PitNEC - may exist if the NET principles are applied in pituitary tumor pathology. Casar-Borota et al. [4] examined 30 aggressive PitNET and 18 pituitary carcinomas and found negative immunostainings for ATRX protein (Alpha thalassemia/mental retardation syndrome, $\mathrm{x}$-linked) in $13 \%$ of aggressive PitNETs and in $28 \%$ of carcinomas. Additionally, they found a strongly increased risk for clinically silent corticotroph PitNETs to have metastatic dissemination.

The demonstration of p53 in pituitary tumor nuclei was described by Kovacs et al. (2013) [8], but this tumor showed $15 \mathrm{Ki} 67$ positive nuclei in 10 high power fields, which does not correspond to a very high Ki67 index. Further studies describe the Ki67 index but not the P53 status: MacCormack et al. (2018) [11] found Ki67 indexes between 10 and $38 \%$ in 40 pituitary carcinomas. Thapar et al. (1996) detected K67 indexes between 0 and 22\% in
7 carcinomas [18], or Ki67 indexes between 0 and 16\% [19]. A case report from Lin et al. [9] deals with a pituitary ACTH-producing PitNET causing Cushing's disease with metastasis to the liver that manifested a mitotic index of up to $50 \%$. Molecular pathology revealed an amplification of $C C N D 3$ (Cyclin D3 protein coding gene), homozygous deletion of PTPRD (protein tyrosine phosphatase, receptor type D), and in the liver pathway, activation of PI3K (Phosphoinositid-3-Kinasen) via subclonal PIK3CA G1050D hot spot mutation. Next-generation sequencing by Majd et al. [10] revealed gene alterations in four pituitary ACTH-producing carcinomas after therapy with pembrolizumab.

Pituitary pathologists should discuss the distinction of NET G3 and NEC. We propose to delineate all differentiated pituitary tumors with a Ki67 index of more than $50 \%$ and the presence of p53 mutation as PitNET G3, as most of these develop metastases, and the undifferentiated/poorly differentiated tumors as PitNEC. Then clinicians can formulate guidelines for postoperative control examinations and therapies. The old principle of referring to tumors as carcinomas according to the existence of metastasis appears absolutely unsuitable for patients and clinicians.

Acknowledgements The tumors included in the present study were drawn from the German Registry of Pituitary Tumours, which is sponsored by Novartis Pharma GmbH (Nürnberg), Novo Nordisk Pharma $\mathrm{GmbH}$ (Mainz), Phizer Pharma GmbH (Karlsruhe), and Ipsen Pharma $\mathrm{GmbH}$ (Ettlingen). The authors thank Kara Leigh Krajewski M.D. for kindly revising the manuscript for suitable English language.

Funding Open Access funding enabled and organized by Projekt DEAL.

\section{Declarations}

Ethical Approval All procedures performed in studies involving human participants were in accordance with the ethical standards of the institutional and/or national research committee and with the 1964 Helsinki declaration and its later amendments or comparable ethical standards (a separate ethic review and permission of a local committee was not necessary according to $\S 12$ to the Hamburgisches Krankenhausgesetz, Hamburg, Germany).

Conflict of Interest The authors declare no competing interests.

Open Access This article is licensed under a Creative Commons Attribution 4.0 International License, which permits use, sharing, adaptation, distribution and reproduction in any medium or format, as long as you give appropriate credit to the original author(s) and the source, provide a link to the Creative Commons licence, and indicate if changes were made. The images or other third party material in this article are included in the article's Creative Commons licence, unless indicated otherwise in a credit line to the material. If material is not included in the article's Creative Commons licence and your intended use is not permitted by statutory regulation or exceeds the permitted use, you will need to obtain permission directly from the copyright holder. To view a copy of this licence, visit http://creativecommons.org/licenses/by/4.0/. 


\section{References}

1. Asa,S.L., Asioli,S., Bozkurt,S., Casar-Borota,O., Chinezu,L., Comunoglu,N., Cossu,G., Cusimano,M., Delgrange,E., Earls,P., Ezzat,S., Gazioglu,N., Grossman,A., Guaraldi,F., Hickman,R.A., Ikeda,H., Jaffrain-Rea,M.L., Karavitaki,N., Kraljevic,I., La Rosa,S., Manojlovic-Gacic,E., Maartens,N., McCutcheon,I.E., Messerer,M., Mete,O., Nishioka,H., Oz,B., Pakbaz,S., Pekmezci,M., Perry,A., Reiniger,L., Roncaroli,F., Saeger,W., Soylemezoglu,F., Tachibana,O., Trouillas,J., Turchini,J., Uccella,S., Villa,C., Yamada,S., Yarman,S.: Pituitary neuroendocrine tumors (PitNETs): nomenclature evolution, not clinical revolution. Pituitary 23: 322-325 (2020)

2. Asa,S.L., Casar-Borota,O., Chanson,P., Delgrange,E., Earls,P., Ezzat,S., Grossman,A., Ikeda,H., Inoshita,N., Karavitaki,N., Korbonits,M., Laws,E.R., Lopes,M.B., Maartens,N., McCutcheon,I.E., Mete,O., Nishioka,H., Raverot,G., Roncaroli,F., Saeger,W., Syro,L.V., Vasiljevic,A., Villa,C., Wierinckx,A., Trouillas,J.: From pituitary adenoma to pituitary neuroendocrine tumor (PitNET): an International Pituitary Pathology Club proposal. Endocrine-Related Cancer 24: C5-C8 (2017)

3. Asa,S.L., Mete,O., Cusimano,M.D., McCutcheon,I.E., Perry,A., Yamada,S., Nishioka,H., Casar-Borota,O., Uccella,S., La Rosa,S., Grossman,A.B., Ezzat,S.: Pituitary neuroendocrine tumors: a model for neuroendocrine tumor classification. Mod Pathol (2021)

4. Casar-Borota,O., Boldt,H.B., Engstrom,B.E., Andersen,M.S., Baussart,B., Bengtsson,D., Berinder,K., Ekman,B., FeldtRasmussen,U., Hoybye,C., Jorgensen,J.O.L., Kolnes,A.J., Korbonits,M., Rasmussen,A.K., Lindsay,J.R., Loughrey,P.B., Maiter,D., Manojlovic-Gacic,E., Pahnke,J., Poliani,P.L., Popovic,V., Ragnarsson,O., Schalin-Jantti,C., Scheie,D., Toth,M., Villa,C., Wirenfeldt,M., Kunicki,J., Burman,P.: Corticotroph Aggressive Pituitary Tumors and Carcinomas Frequently Harbor ATRX Mutations. Journal of Clinical Endocrinology \& Metabolism 106: 1183-1194 (2021)

5. Chopin-Laly,X., Walter,T., Hervieu,V., Poncet,G., Adham,M., Guibal,A., Chayvialle,J.A., Lombard-Bohas,C., Scoazec,J.Y.: Neuroendocrine neoplasms of the jejunum: a heterogeneous group with distinctive proximal and distal subsets. Virchows Archiv 462: 489-499 (2013)

6. Guo,F.Y., Wang,G.Q., Wang,F., Xu,D.K., Liu,X.Z.: Identification of Novel Genes Involved in the Pathogenesis of an ACTH-Secreting Pituitary Carcinoma: A Case Report and Literature Review. Frontiers in Oncology 8: 510. https://doi.org/10.3389/fonc.2018.00510. eCollection (2018)

7. Klimstra,D.S., Klöppel,G., La Rosa,S., Rindi,G.: Classification of neuroendocrine neoplasms of the digestive system. In: Edited by Arends,M.J., Fukuyama,M., Klimstra,D.S., Lam,A.K.Y., Nagtegaal,I.D., Odze,R.D.: WHO Classification of Tumours: Digestive system Tumors, Ed.5: pp.17-22. International Agency for Research and Cancer (IARC), Lyon: (2019)

8. Kovacs,G.L., Goth,M., Rotondo,F., Scheithauer,B.W., Carlsen,E., Saadia,A., Hubina,E., Kovacs,L., Szabolcs,I., Nagy,P., Czirjak,S., Hanzely,Z., Kovacs,K., Horvath,E., Korbonits,M.: ACTH-secreting Crooke cell carcinoma of the pituitary. Eur.J.Clin.Invest. 43: 20-26 (2013)

9. Lin,A.L., Jonsson,P., Tabar,V., Yang,T.J., Cuaron,J., Beal,K., Cohen,M., Postow,M., Rosenblum,M., Shia,J., DeAngelis,L.M., Taylor,B.S., Young,R.J., Geer,E.B.: Marked Response of a
Hypermutated ACTH-Secreting Pituitary Carcinoma to Ipilimumab and Nivolumab. Journal of Clinical Endocrinology \& Metabolism 103: 3925-3930 (2018)

10. Majd,N., Waguespack,S.G., Janku,F., Fu,S.Q., Penas-Prado,M., Xu,M.X., Alshawa,A., Kamiya-Matsuoka,C., Raza,S.M., McCutcheon,I.E., Naing,A.: Efficacy of pembrolizumab in patients with pituitary carcinoma: report of four cases from a phase II study. Journal for Immunotherapy of Cancer 8: (2020)

11. McCormack,A., Dekkers,O.M., Petersenn,S., Popovic,V., Trouillas,J., Raverot,G., Burman,P.: Treatment of aggressive pituitary tumours and carcinomas: results of a European Society of Endocrinology (ESE) survey 2016. Eur J Endocrin 178: 265$276(2018)$

12. Osamura,R., Lopes,M.B.S., Grossman,A., Kontogeorgos,G., Trouillas,J.: Tumours of the pituitary gland. In: Edited by Lloyd,R.V., Osamura,R.Y., Klöppel,G., Rosai,J.: WHO classification of tumours of endocrine organs, Ed.4th: pp.11-64. Springer, Heidelberg-Berlin: (2017)

13. Pasquel,F.J., Vincentelli,C., Brat,D.J., Oyesiku,N.M., Ioachimescu,A.G.: Pituitary Carcinoma in Situ. Endocrine Practice 19: E69-E73 (2013)

14. Rindi,G., Klimstra,D.S., Abedi-Ardekani,B., Asa,S.L., Bosman,F.T., Brambilla,E., Busam,K.J., de Krijger,R.R., Dietel,M., El-Naggar,A.K., Fernandez-Cuesta,L., Kloppel,G., McCluggage,W.G., Moch,H., Ohgaki,H., Rakha,E.A., Reed,N.S., Rous,B.A., Sasano,H., Scarpa,A., Scoazec,J.Y., Travis,W.D., Tallini,G., Trouillas,J., van Krieken,J.H., Cree,I.A.: A common classification framework for neuroendocrine neoplasms: an International Agency for Research on Cancer (IARC) and World Health Organization (WHO) expert consensus proposal. Mod Pathol 31: 1770-1786 (2018)

15. Saeger,W., Koch,A.: Clinical Implications of the New WHO Classification 2017 for Pituitary Tumors. Exper clin Endocr Metab 129: 146-156 (2021)

16. Sautner,D., Saeger,W.: Invasiveness of pituitary adenomas. Pathol Res Pract 187: 632-636 (1991)

17. Tani,Y., Sugiyama,T., Izumiyama,H., Yoshimoto,T., Yamada,S., Hirata,Y.: Differential gene expression profiles of POMC-related enzymes, transcription factors and receptors between non-pituitary and pituitary ACTH-secreting tumors. Endocrine Journal 58: 297 $303(2011)$

18. Thapar,K., Kovacs,K., Scheithauer,B.W., Stefaneanu,L., Horvath,E., Pernicone,P.J., Murray,D., Laws,E.R., Jr.: Proliferative activity and invasiveness among pituitary adenomas and carcinomas: An analysis using the MIB-1 antibody. Neurosurgery 38: 99-106 (1996)

19. Thapar,K., Yamada,Y., Scheithauer,B.W., Kovacs,K., Yamada,S., Stefaneanu,L.: Assessment of mitotic activity in pituitary adenomas and carcinomas. Endocr Pathol 7: 215-221 (1996)

20. Walter,T., Hervieu,V., Adham,M., Gincul,R., Poncet,G., Pilleul,F., Chayvialle,J.A., Partensky,C., Lombard-Bohas,C., Scoazec,J.Y.: Primary neuroendocrine tumors of the main pancreatic duct: a rare entity. Virchows Archiv 458: 537-546 (2011)

Publisher's Note Springer Nature remains neutral with regard to jurisdictional claims in published maps and institutional affiliations. 